\title{
Affinity-Driven Immobilization of Proteins to Hematite Nanoparticles
}

Elaheh Zare-Eelanjegh†, Debajeet K. Bora $\downarrow$, Patrick Rupper ${ }^{\dagger}$, Krisztina Schrantz $\ddagger$ Linda ThönyMeyer†, Katharina Maniura-Weber†, Michael Richter†, Greta Faccio ${ }^{*} *$

$\dagger$ Laboratory for Biointerfaces, Empa, Swiss Federal Laboratories for Materials Science and Technology, Lerchenfeldstrasse 5, 9014 St. Gallen (Switzerland).\$Laboratory for High Performance Ceramics, Empa, Swiss Federal Laboratories for

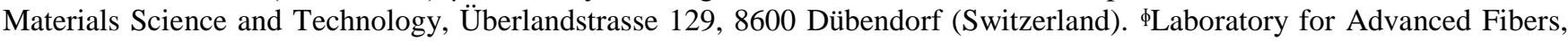
Empa, Swiss Federal Laboratories for Materials Science and Technology, Lerchenfeldstrasse 5, 9014 St. Gallen (Switzerland).

\section{Corresponding Author}

* Dr. Greta Faccio, Laboratory for Biointerfaces, Empa - Swiss Federal Laboratories for Materials Science and Technology, Lerchenfeldstrasse 5, 9014 St. Gallen (Switzerland), Tel +41 587657262. 


\section{TABLE OF CONTENTS}

Table S1. Oligonucleotides and plasmids $\quad$ S-3

Table S2 Comparison of the physico-chemical properties of the proteins used $\quad$ S-4

Table S3 Effect of TEV treatment on the different CPC variants $\quad$ S-5

Figure S1 Surface potential of LACC and CPC $\quad$ S-6

$\begin{array}{lr}\text { Figure S2 SDS PAGE analysis of CPC-NP complexes } & \text { S-7 }\end{array}$

$\begin{array}{ll}\text { Figure S3 FESEM images of hematite NP } & \text { S-8 }\end{array}$

Figure S4 SDS PAGE analysis of CPC-NP complexes at different CPC concentration S-9

Figure S5 SDS PAGE of HemLACC purification and protein identification $\quad$ S-10

Figure S6 Visualization of surface exposed histidines in LACC $\quad$ S-11

Figure S7 Effect of immobilization on laccase activity $\quad$ S-12

Figure S8 pH behavior of HemLACC in the free and immobilized form $\quad$ S-13 
Table S1. Oligonucleotides and plasmids used for the cloning of the Hem-tagged CPC and LACC variants.

\begin{tabular}{|c|c|c|c|c|}
\hline Construct & Plasmid & $\begin{array}{l}\text { Primer } \\
\text { ID }\end{array}$ & Modification & Sequence $\left(5^{\prime} \rightarrow 3^{\prime}\right)$ \\
\hline HisCPC & $\begin{array}{l}\text { pBS414V } \\
\text { and } \\
\text { pAT101v }\end{array}$ & 1 & - & - \\
\hline $\begin{array}{l}\text { B. pumilus } \\
\text { laccase }\end{array}$ & $\mathrm{pBul}^{18}$ & T- & - & - \\
\hline HisHemCРC & pGF024 & $\begin{array}{l}\text { CPC- } \\
\text { FW+His }\end{array}$ & $\begin{array}{l}\text { N-terminal Hem- } \\
\text { tag to HisCPC }\end{array}$ & $\begin{array}{l}\text { GATAACAATTTCACACAGGAAACAGACCATGAGCA } \\
\text { CCGTGCAGACCATTAGCCCGAGCAACCATCATCATC } \\
\text { ATCATCATCACGATTACGATATC }\end{array}$ \\
\hline HemCPC & pGF023 & $\begin{array}{l}\text { HemCP } \\
\text { C-FW- } \\
\text { Histag } \\
\end{array}$ & $\begin{array}{l}\text { N-terminal Hem- } \\
\text { tag to CPC }\end{array}$ & $\begin{array}{l}\text { GATAACAATTTCACACAGGAAACAGACATGAGCAC } \\
\text { CGTGCAGACCATTAGCCCGAGCAACCATGATTACGA } \\
\text { TATCCCAACGACCG }\end{array}$ \\
\hline & & CPC rev & $\begin{array}{l}\mathrm{N} \text {-terminal Hem- } \\
\text { tag to CPC }\end{array}$ & $\begin{array}{l}\text { CCTTGTCGACGTAGGCCTTTGAATTCGAAGACTAGC } \\
\text { TCAGAGCATTGATGGCG }\end{array}$ \\
\hline HemLACC & pGF045 & $\begin{array}{l}\text { TEV- } \\
\text { HemLA } \\
\text { CC }\end{array}$ & $\begin{array}{l}\text { N-terminal Hem- } \\
\text { tag and TEV-site to } \\
\text { LACC }\end{array}$ & $\begin{array}{l}\text { CCATTAGCCCGAGCAACCATGAAAACCTGTATTTTC } \\
\text { AGGGCATGAACCTAGAAAAATTTG }\end{array}$ \\
\hline
\end{tabular}


Table S2 Comparison of the physico-chemical properties of the proteins and tags used.

\begin{tabular}{|c|c|c|c|c|}
\hline & $\mathrm{CPC}^{\mathrm{a}}$ & HisCPC $^{d}$ & LACC & Hem-tag \\
\hline Organism & Arthrospira sp. & $\begin{array}{l}\text { Synechocystis } \\
\text { PCC6803 }\end{array}$ & Bacillus pumilus & - \\
\hline MW & $\begin{array}{l}\alpha^{b}: 17601 \\
\beta^{c}: 18093\end{array}$ & 20463 & 58725 & 1170 \\
\hline $\mathrm{pI}$ & $\begin{array}{l}\alpha^{\mathrm{b}}: 5.8 \\
\beta^{\mathrm{c}}: 4.9\end{array}$ & 5.8 & 5.9 & 6.5 \\
\hline $\begin{array}{l}\text { Negatively charged } \\
\text { (Asp, Glu) }\end{array}$ & $\begin{array}{l}\alpha: 9+8 \\
\beta: 10+8\end{array}$ & $13+7$ & $31+31$ & $0+0$ \\
\hline $\begin{array}{l}\text { Positively charged } \\
\text { (His, Lys, Arg) }\end{array}$ & $\begin{array}{l}\alpha: 1+9+7 \\
\beta: 0+4+11\end{array}$ & $8+7+8$ & $23+26+29$ & $1+0+0$ \\
\hline Cys & $\alpha: 2, \beta: 4$ & 2 & 5 & 0 \\
\hline
\end{tabular}


Table S3 Effect of TEV treatment on the different CPC variants.

\begin{tabular}{|l|c|c|c|c|c|c|}
\hline & & TEV & HemCPC & HemHisCPC & HisCPC & CPC \\
\hline \multirow{2}{*}{ Total protein } & \multirow{2}{*}{ A295 } & + & $2.77 \pm 0.21$ & $0.30 \pm 0.02$ & $0.33 \pm 0.01$ & $0.35 \pm 0.01$ \\
\cline { 3 - 7 } & & - & $3.30 \pm 0.22$ & $0.31 \pm 0.02$ & $0.33 \pm 0.01$ & $0.22 \pm 0.00$ \\
\hline \multirow{2}{*}{ CPC absorption } & \multirow{2}{*}{ A620 } & + & $0.58 \pm 0.05$ & $0.40 \pm 0.02$ & $0.53 \pm 0.04$ & $0.37 \pm 0.00$ \\
\cline { 3 - 7 } & & - & $0.98 \pm 0.34$ & $0.40 \pm 0.01$ & $0.49 \pm 0.01$ & $0.35 \pm 0.01$ \\
\hline \multirow{2}{*}{ CPC fluorescence } & \multirow{2}{*}{ F640 } & + & $276 \pm 66$ & $356 \pm 20$ & $470 \pm 18$ & $281 \pm 30$ \\
\cline { 3 - 7 } & & - & $292 \pm 63$ & $393 \pm 40$ & $487 \pm 49$ & $338 \pm 24$ \\
\hline
\end{tabular}



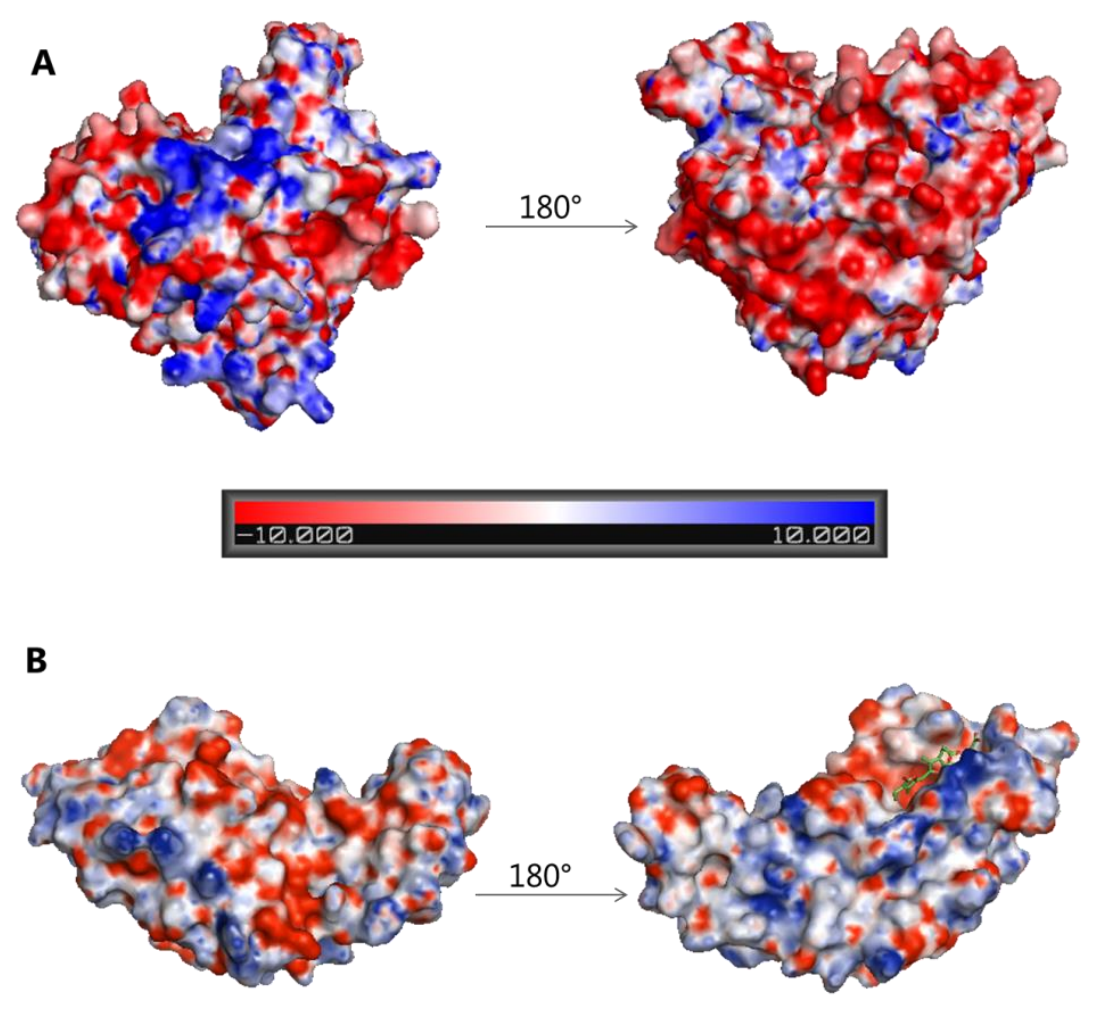

$-10.000$

Figure S1 Three dimensional structure model of LACC (A) and CPC ( $\alpha$-subunit, PDB ID: 4F0T) (B) showing regions of positive and negative potential on the surface. The LACC molecule was modelled using the available structure of CotA from Bacillus subtilis (PDB ID: 1GSK, 69\% sequence identity) by substituting the corresponding residues after a sequence alignment ${ }^{44}$. 


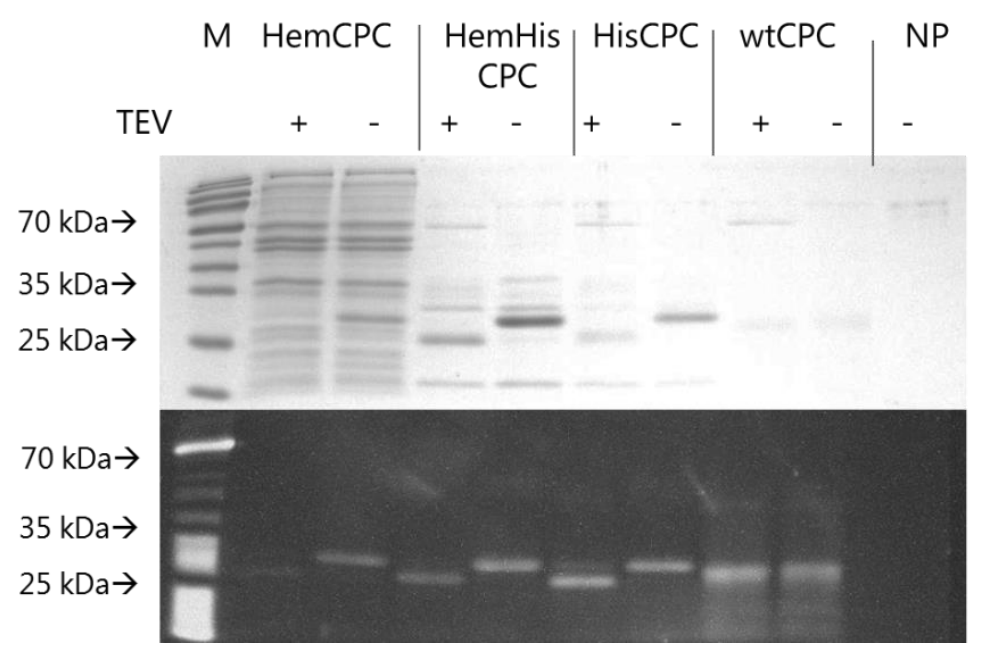

Figure S2 Binding of CPC variants to hematite nanoparticles. SDS PAGE analysis of the nanoparticles after incubation with the CPC variants by SDS PAGE that was stained with Coomassie (upper panel) and zinc acetate (specific bilin staining, lower panel). 

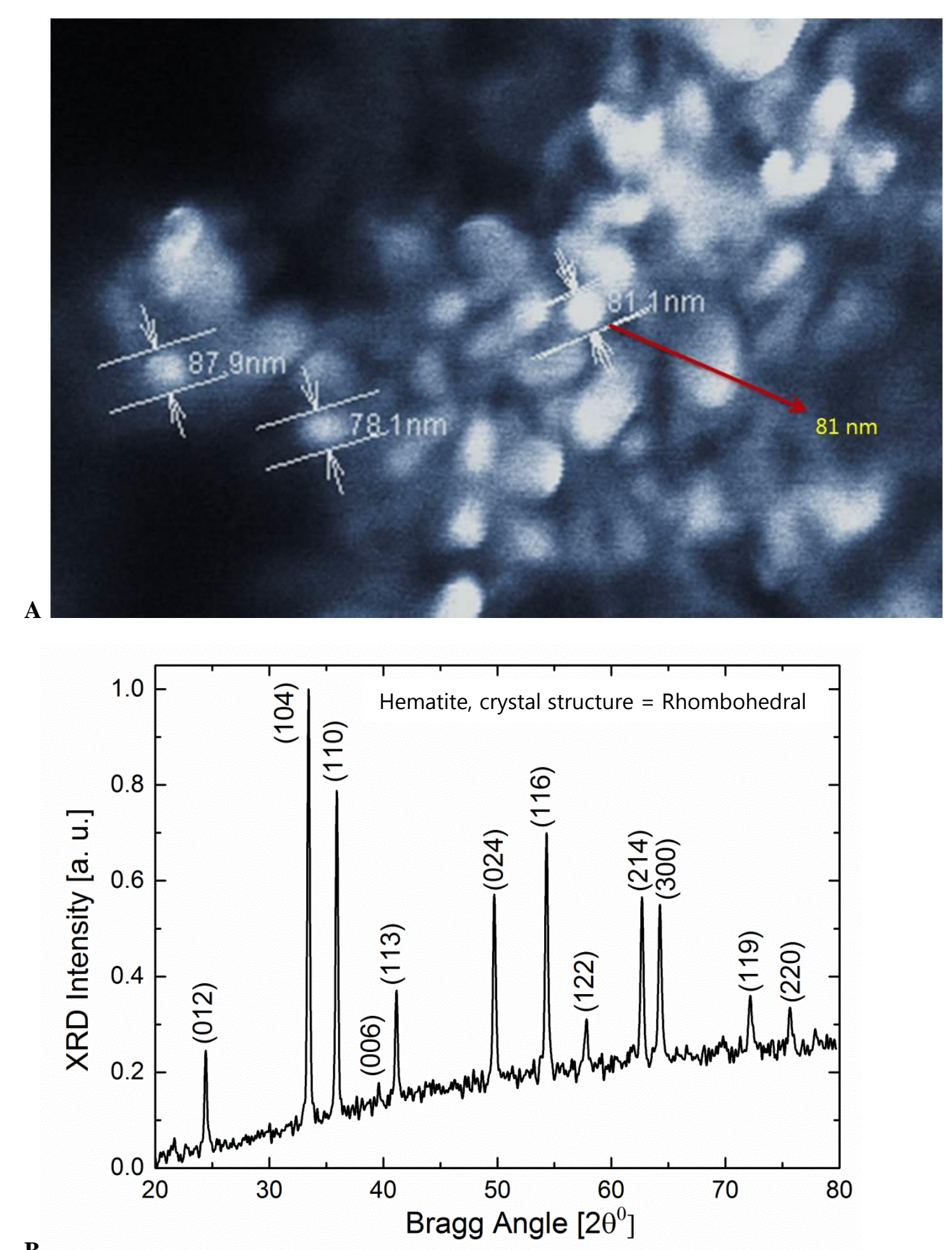

B

Figure S3: (A) FESEM of bare hematite nanoparticles in ethanol dispersed form, (B) X-ray diffractogram of hematite nanoparticles. 

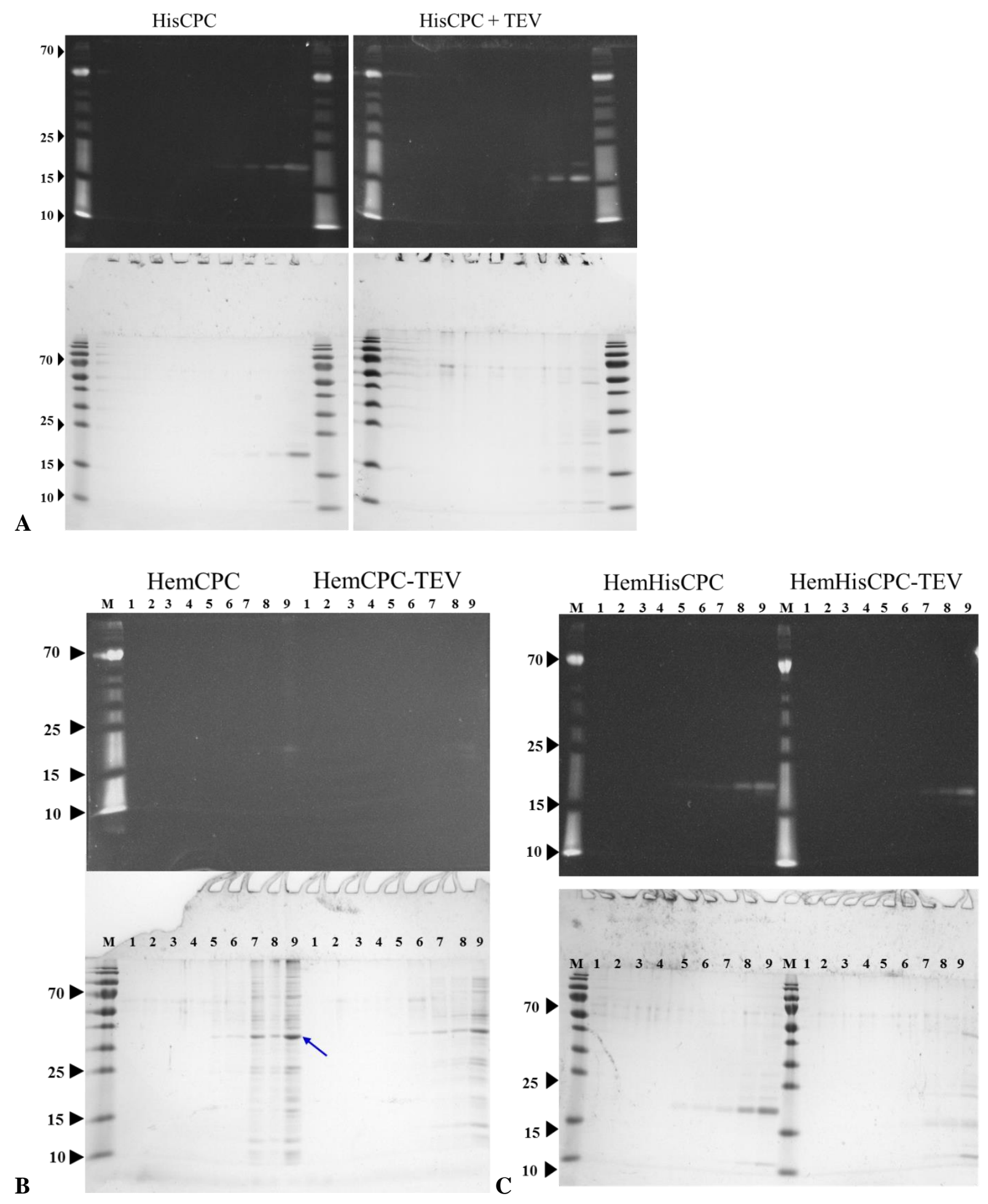

Figure S4 SDS PAGE analysis of hematite nanoparticles after incubation at different concentration of HisCPC (A), HemCPC (B), or HemHisCPC (C). Lane 1: $0 \mathrm{mg} / \mathrm{ml} \mathrm{CPC} \mathrm{variant,} \mathrm{2:0.00007} \mathrm{mg/ml} \mathrm{CPC} \mathrm{variant,} \mathrm{3:} 0.0003$ $\mathrm{mg} / \mathrm{ml} \mathrm{CPC} \mathrm{variant,} \mathrm{4:} 0.0007 \mathrm{mg} / \mathrm{ml} \mathrm{CPC} \mathrm{variant,} \mathrm{5:0.003} \mathrm{mg/ml} \mathrm{CPC} \mathrm{variant,} \mathrm{6:0.007} \mathrm{mg/ml} \mathrm{CPC} \mathrm{variant,}$ 7:0.03 $\mathrm{mg} / \mathrm{ml} \mathrm{CPC} \mathrm{variant,} \mathrm{8:0.07} \mathrm{mg} / \mathrm{ml} \mathrm{CPC} \mathrm{variant,} \mathrm{9:0.3} \mathrm{mg} / \mathrm{ml} \mathrm{CPC} \mathrm{variant.} \mathrm{The} \mathrm{protein} \mathrm{band} \mathrm{indicated} \mathrm{by}$ the arrow was subjected to peptide mass fingerprinting for identification. 


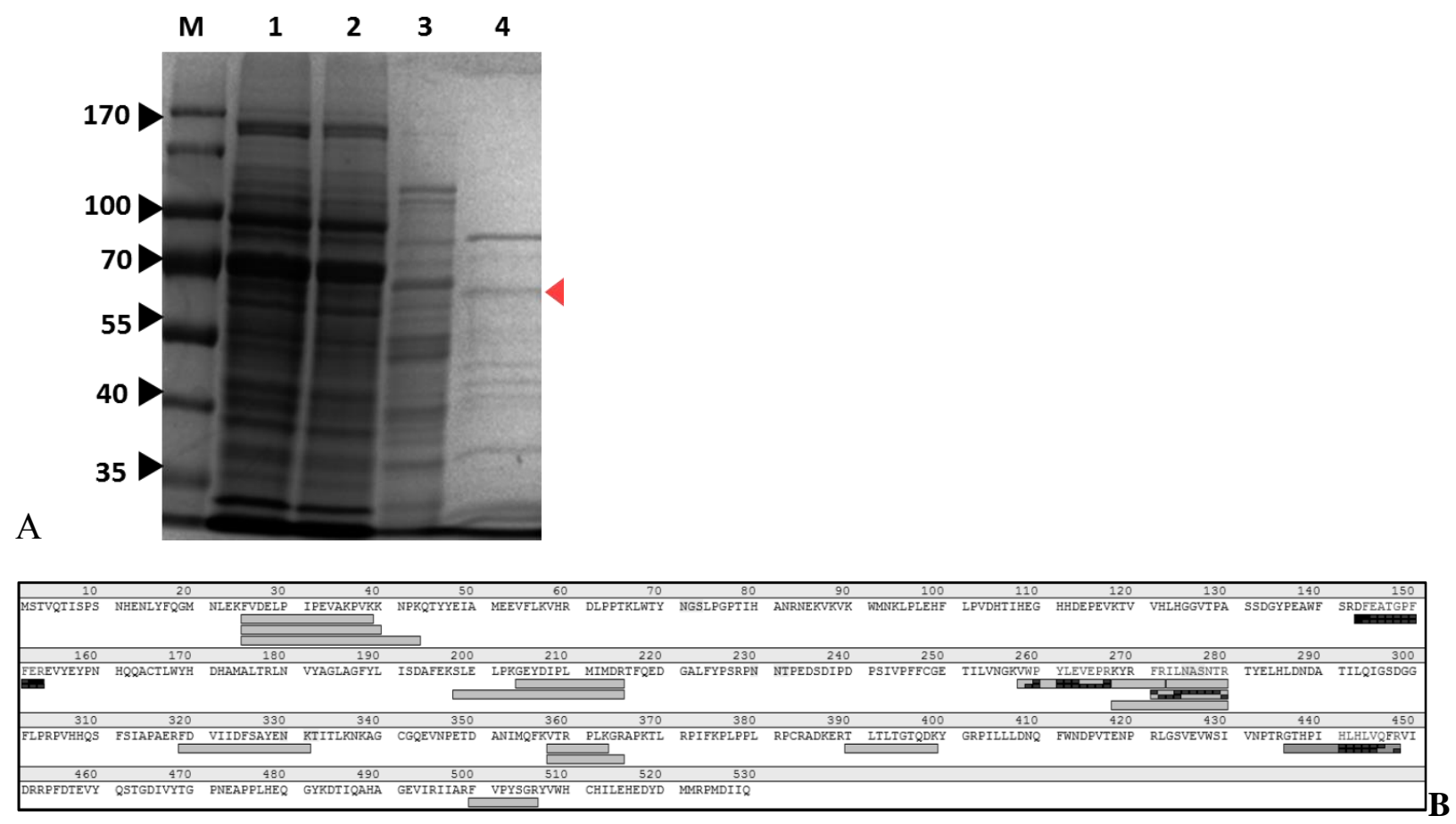

Figure S5 (A) SDS PAGE of partially purified HemLACC (lane 4), cell-free extract (lane 1), material not binding to the column (lane 2), and the first fraction eluted at $\sim 50 \mathrm{~m} \mathrm{M}$ imidazole (lane 3). Molecular weight markers are reported in $\mathrm{kDa}$ on the left (lane $\mathrm{M}$ ). (B) The band corresponding to HemLACC is indicated by a red arrow tip and was identified by peptide mass fingerprinting. The detected peptides ascribed to HemLACC are indicated by grey boxes below the corresponding protein sequence. 

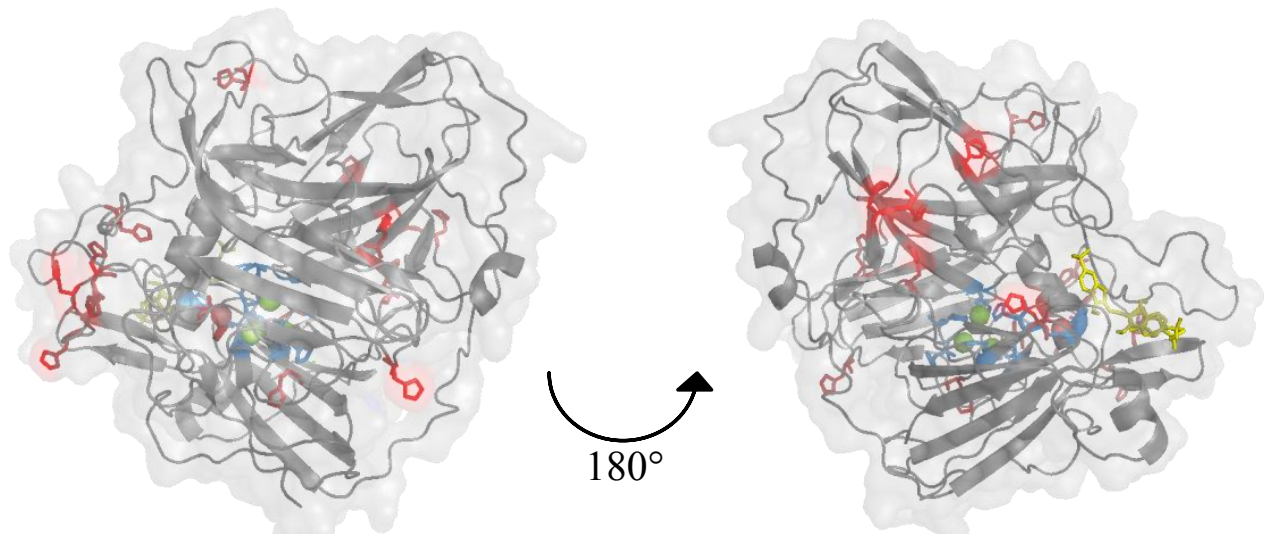

Figure S6 Three-dimensional model of LACC showing the histidine residues that are exposed on the surface (red) or in proximity of the copper ions (blue). The LACC molecule was modelled using the available structure of CotA from Bacillus subtilis binding an ABTS molecule (yellow) by substituting the corresponding residues after a sequence alignment ${ }^{44}$. 


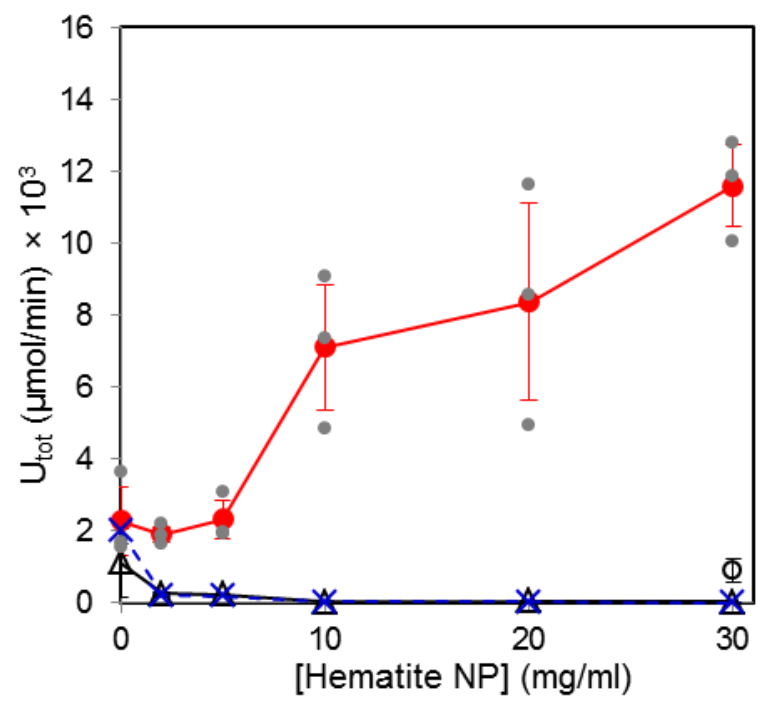

Figure S7 Effect of immobilization on laccase activity. A constant amount of HemLACC was incubated in the presence of different amounts of nanoparticles and the activity was measured from the immobilized fraction (red line with dots showing the raw values as grey dots), the unbound fraction (black line with triangles), from a first rinsing of the nanoparticles in buffer (blue dashed line with crosses), and from an untreated NP sample (empty dot) that was used as negative control. 


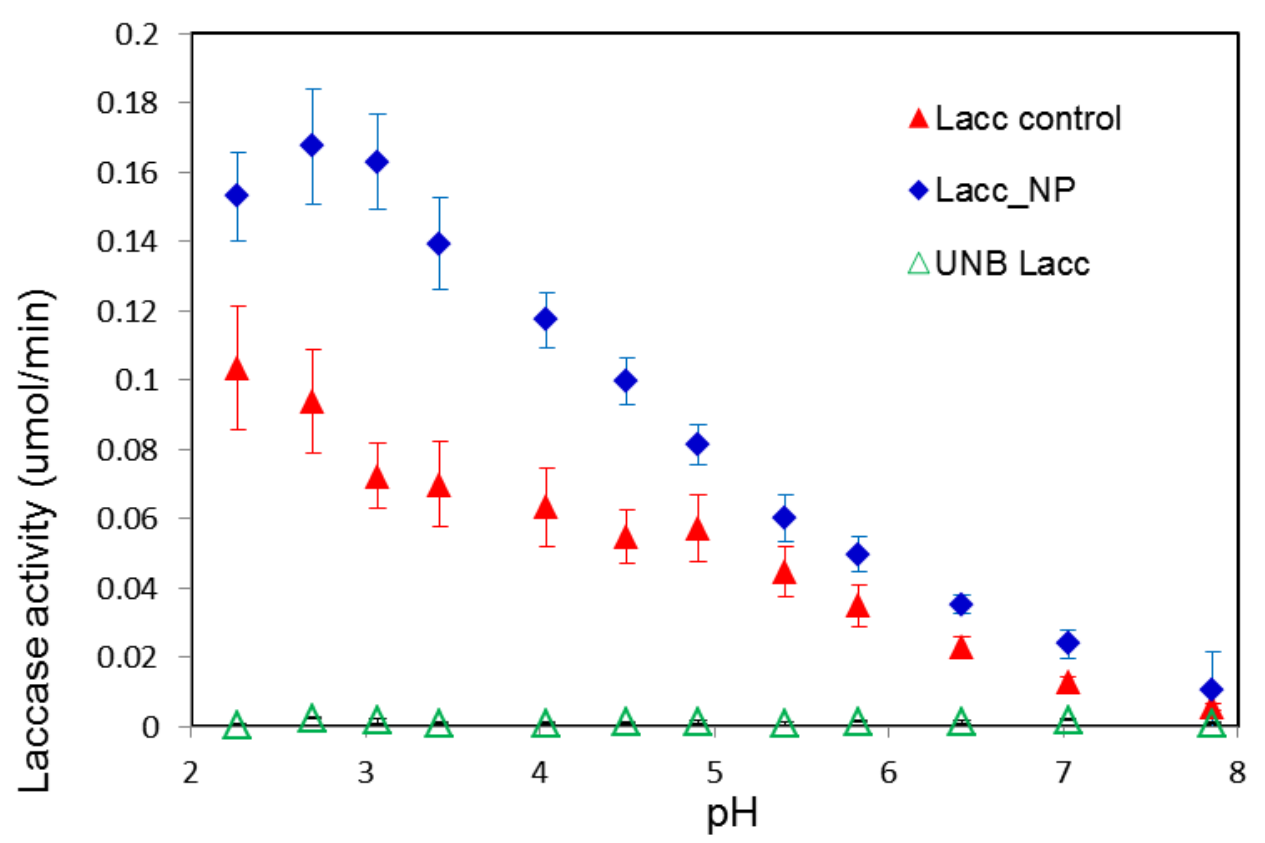

Figure S8 pH behavior of HemLACC in the free form (red triangles), in the immobilized form (blue diamonds), and as the unbound fraction (empty green triangles) obtained from the immobilization procedure.

\section{References}

(44) Wang, Y., Addess, K. J., Chen, J., Geer, L. Y., He, J., He, S., Lu, S., Madej, T., Marchler-Bauer, A., Thiessen, P. A., Zhang, N.; Bryant, S. H. MMDB: Annotating Protein Sequences with Entrez's 3D-Structure Database Nucleic Acids Res. 2007,35 , D298. 